UNITED STATES DEPARTMENT OF THE INTERIOR GEOLOGICAL SURVEY

PRELIMINARY GEOMAGNETIC DATA COLLEGE OBSERVATORY FAIRBANKS, ALASKA

JUNE 1984

OPEN FILE REPORT 84-0300F

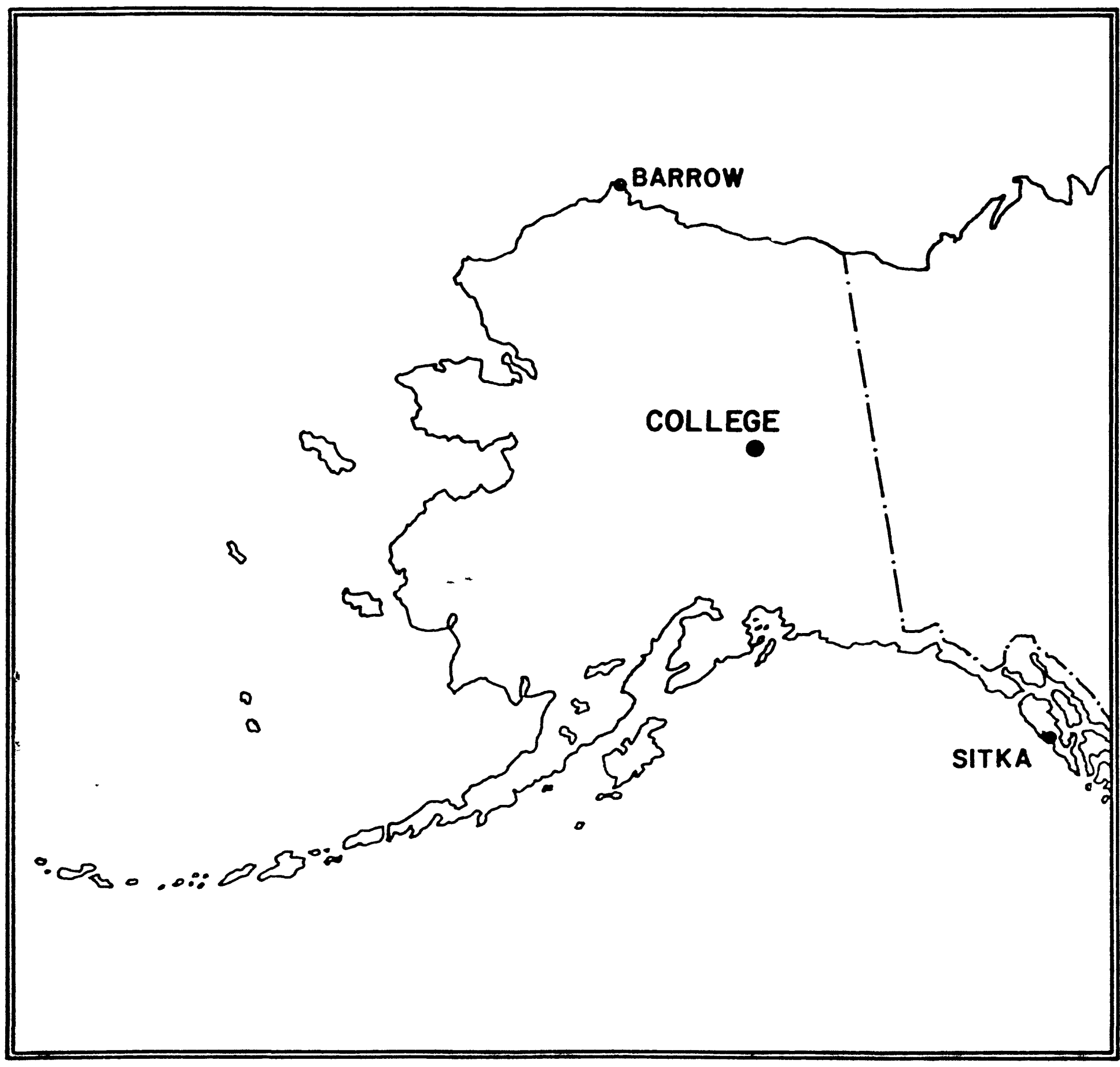


THIS REPORT WAS PREPARED UNDER THE DIRECTION OF JOHN B. TOWNSHEND, CHIEF OF THE COLLEGE OBSERVATORY, WITH THE ASSISTANCE OF THE OBSERVATORY STAFF MEMBERS: J,E, PAPP, E,A. SAUTER, L,Y, TORRENCE, $P, A$. FRANKLIN AND IN COOPERATION WITH THE GEOPHYSICAL INSTITUTE OF THE UNIVERSITY OF ALASKA. THE COLLEGE OBSERVATORY IS A PART OF THE BRANCH OF GLOBAL SEISMOLOGY AND GEOMAGNETISM OF THE U.S. GEOLOGICAL SURVEY.

Explanation of Data and Reports

Magnetic Activity Report

Outstanding Magnetic Effects

Principal Magnetic Storms

Preliminary Calibration Data and Monthly Mean Absolute Values

Magnetogram Hourly Scalings

Sample Format for Normal and Storm Magnetograms

Normal Magnetograms

Storm Magnetograms (When Normal is too disturbed to read) 
The preliminary geomagnetic data included here is made available to scientific personnel and organizations os part of a cooperative effort and on a data exchange basis because of the eariy need by some users. To avoid delay, all of the data is copied from original forms processed at the observatory; therefore it should be regarded as preliminary. Inquiries about this report or about the College Observatory should be addressed to:

Chief, College Observatory

U.S. Geological Survey

Fairbanks, Alaska 99701

Requests for copies of the magnetograms except for the current month should be addressed to:

World Data Center A

NOAA D63, 325 Broadway

Boulder, Colorado 80303
800 Yukon Drive

The College Observatory, operated by the U.S. Geological Survey, is located at the University of Alaska, Fairbanks, Alaska. It is near the Auroral Zone and the northern limit of the world's greatest earthquake belt, the circum-Pacific Selsmic belt. Although the observatory's basic operation is in geomagnetism and seismology, it cooperates with other scientists and organizations in areas where the facility and personnel can be of service.

The observatory is one of three operated by the USGS in Alaska. The others are located at Barrow and Sitka.
The position of the observatory site is: Geographic latitude.....6.64 $51.6^{\prime} \mathrm{N}$ Geographic longitude.......1470 50.2'W
Geomagnetic latitude...... +64.60
Geomagnetic longitude...... 256.50
Elevation.............200 meters

\section{GEOMAGNETIC DATA}

Normal, Storm and Rapid Run magnetograms and appropriaze calioration data are processed daily at the oiservatory and are available for analysis or copying. Also available, are mean hourly scalings, $\mathrm{K}$-Indices, selected magnetic phenomena reports and on a real-time basis are recordings from a 3-component fluxgate magnetometer and $\bar{F}$-component proton magnetometer.

\section{iagnetic Activity}

The K-Index: The K-Index is a logarithmic measurement of the range of the most disturbed component ( $D$ or $\mathrm{H})$ of the geomagnetic field for eight intervals beginning 0000-0300, 0300-0600..2100-2400 UT. It is a measure of the difference between the highest and lowest deviation from a smooth curve to be expected for a component on a magnetically quiet day, within a three hour interval.

The Equivalent Daily Amplitude, AK: The K-Index is converted into an equivalent range, $a k$, which is near the center of the limiting gamma ranges for a given $K$. The average of the eight values is called equivalent daily amplitude AK. The unit lor has been chosen so as not to give the illusion of an accuracy not justified. The sciedule for converting gamma range to $K$, and

$K$ to ak is as follows:

\begin{tabular}{c} 
Ganma Range \\
\hline $0<25$ \\
$25<50$ \\
$50<130$ \\
$100<200$ \\
$200<350$ \\
$350<600$ \\
$600<2000$ \\
$1000<1650$ \\
$1650<2500$ \\
$2500+$
\end{tabular}

\begin{tabular}{c}
$K$ - Index \\
\hline 0 \\
1 \\
2 \\
3 \\
4 \\
5 \\
6 \\
7 \\
8 \\
9
\end{tabular}

$\frac{a k}{0}$
3
7
15
27
48
80
140
240
400 (10y)

The :Yaneita Deiiy Character Figure, C: To each vaiversei day a scaracter is assigned on the basis $c=0$, if it is quiet; $c=1$, if it is moderately disturbed; $C=2$, if it is greatly cisturbed. The mettod used to assign characters at the coilege

Observatory is based on AK as follows:

$\begin{array}{ll}\frac{M}{M} \text { Range } & c \\ 0 \approx 11 & \frac{c}{0} \\ i 1 \approx 50 & 2 \\ 50+ & 2\end{array}$

Routine assiznment of $C$ :as discontinued at College on January 1 , 1976.
Selected Phenomena \& Outstanding Magnetic Effests Prior to January 1,1976 , the Norma 1 and Rapid Run records were reviewed at the observatory for selected magnetic phenomena and the events identified were forwarded to the IUGG Commission on Magnetic Variations and Disturbances. This was discontinued on January 1, 1976, but a report on Outstanding lagnetic Effects is prepared monthly for this report.

\section{Principal Magnetic Storms}

Gradual and sudden commencement magnetic disturbances with at least one K-Index of 5 or greater, which are believed to be part of a world-wide disturbance, are classified as principal magnetic storms. The time of the storm beginning and ending; direction and amplitude of sudden commencements; period of maximum activity; and storm range are reported. Monthly reports of these data are forwarded to the World Data Center A in Boulder, Colorado.

\section{Magnetogram Hourly Scalings}

Magnetogram hourly scalings are averages for successive periods of one hour for the $D, H$ and $Z$ elements. The Value in the column headed "O1" is the average for the hour beginning 0000 and ending 0100 . Note that the values on the scaiing sheets are in tentins of mm with the decimal point omitted. The user of these scalings should keep in mind that the tabular values are hourly means and if he is interested in the detailed morphology of the magnetic field, he should refer direct to the magnetograms.

\section{Magnetograns}

The normal magnetograms in this report are reproduced at about one-third the size of the originals. Preliminary base-line values and sals :alues adcr.ted $f o$ use with the original magnetograms are naluced. Far days when the ragretic field is too disturbed for tre Normal magnetogram jo be readable, Storm magnetograms are reproduced. To determine the atsoiute vaiue or the mannetis field from the houriy means or from poin: scalings tre following equations should be used: $D=Z_{m}+d \cdot S_{T} ; H=Z_{\psi}+h \cdot S_{H} ; 2=B_{T}+z \cdot S_{Z}$ where $\mathrm{D}, \mathrm{H}$ and $\mathrm{Z}$ are absolute values; $E_{D}, B_{H}$ and $B_{Z}$ are base-line values; $S_{0}, S_{y}$ and $S_{z}^{2}$ are scale values; and $d, h$ and $z$ are scalings in millimeters.
Absolutes, Ease-iznes and Sale Veiues 
U. S. DEPARTMENT OF COMMERCE
NÜAA FORM 76-133 NATIONAL OCEANIC AND ATMOSPHERIC ADMINISTRATION

MAGNETIC ACTIVITY

(Greenwich civil time, counted from midnight to midnight)
OBSERVATORY

COLLEGE, ALASKA

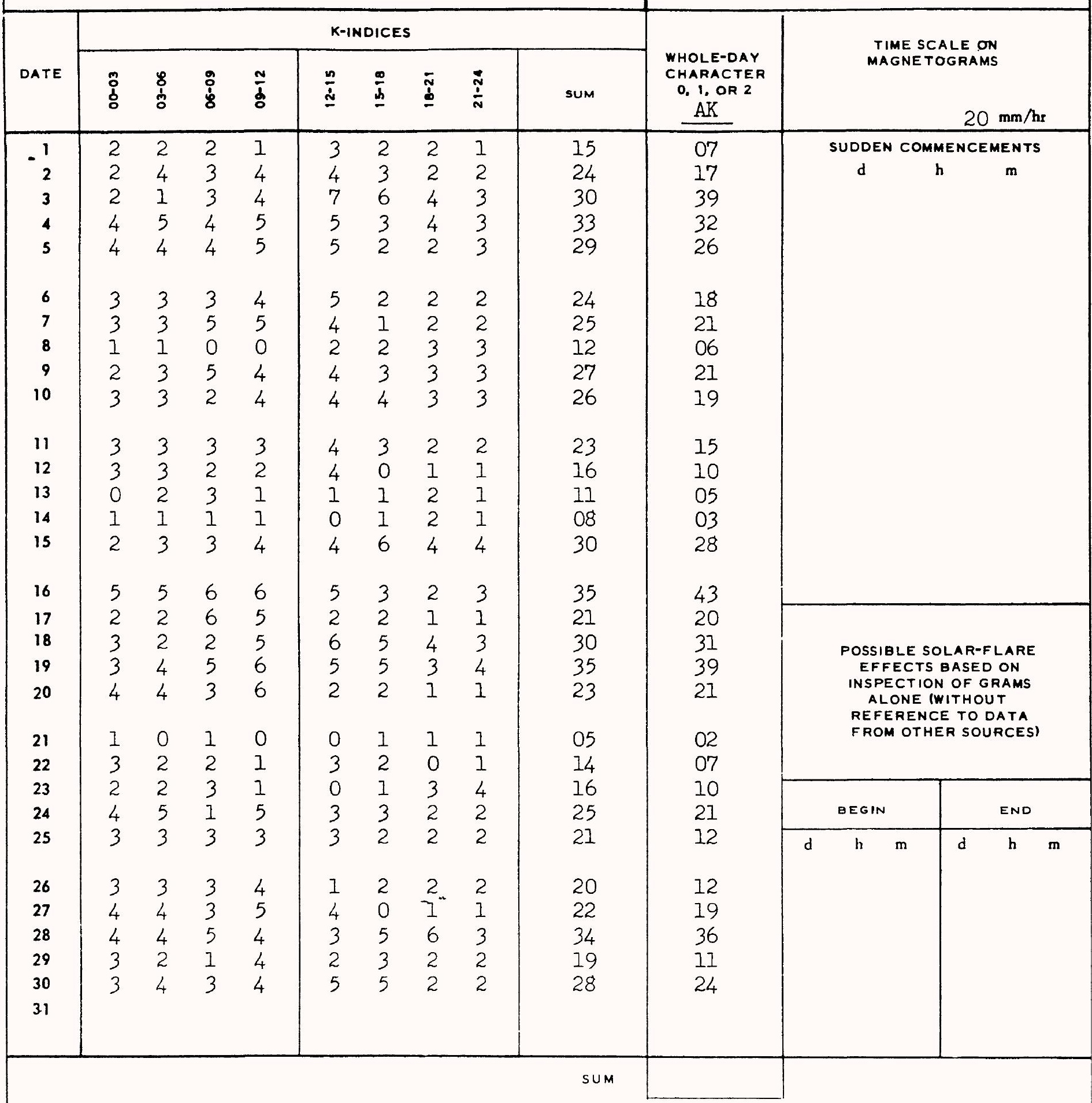

K SCALE USED:

LOWER LIMIT FOR $K=9 . \ldots \ldots$.

CURRENT SCALE VALUE.........

\begin{tabular}{|c|c|c|}
\hline$D$ & $H$ & $z$ \\
\hline 675.7 & 322.2 & \\
\hline 3.72 & 7.83 & \\
\hline 2510 & 2520 & \\
\hline
\end{tabular}

$(\mathrm{mm})$

$(\gamma / \mathrm{mm})$

(to nearest $10 \gamma$ )

LOWER LIMIT FOR K $=9 \ldots \ldots . .$.

APPROVED JOHN B. TOWNSHEND, CHIEF, COLLEGE OBSERVATORY 


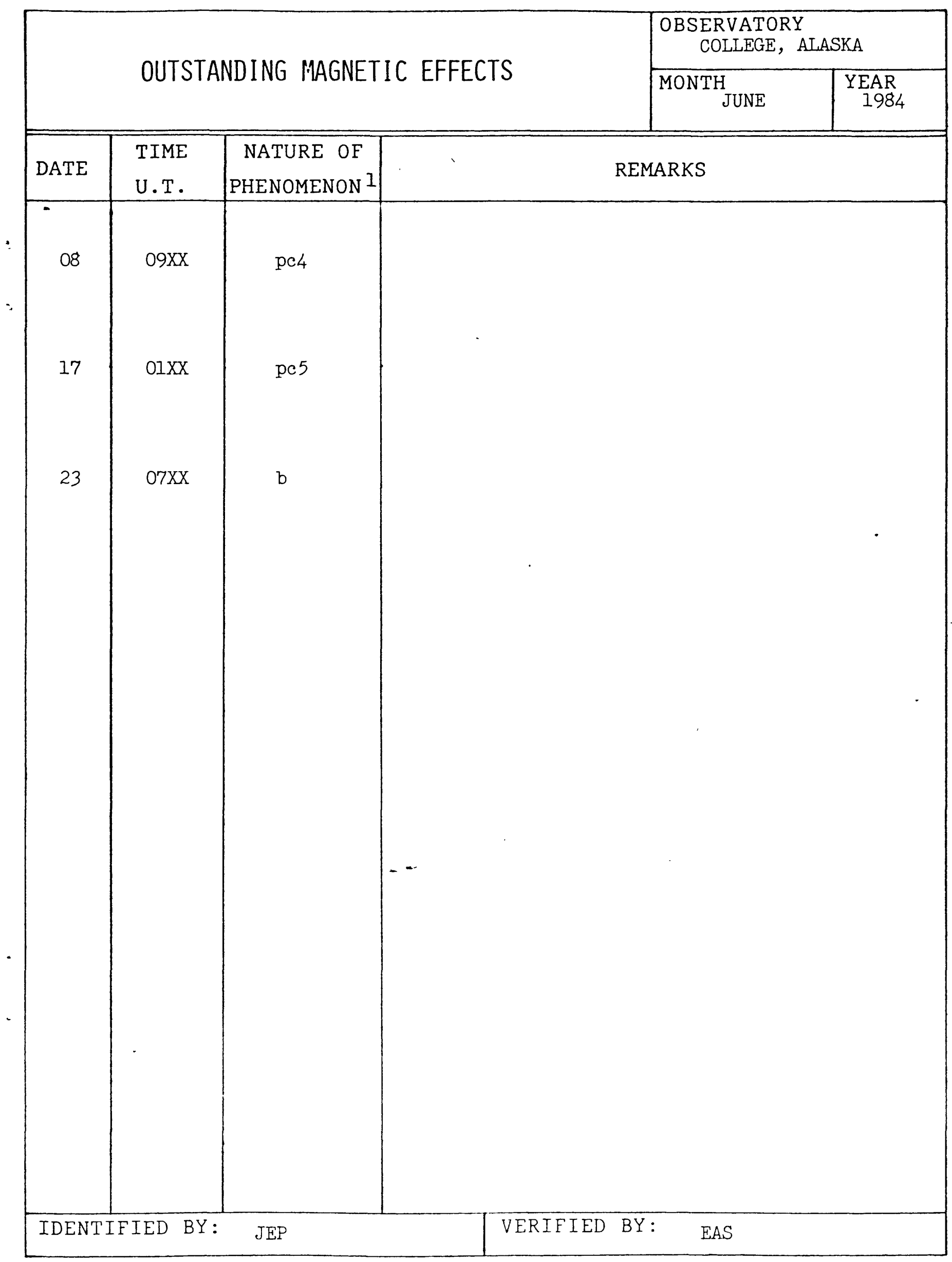

1. NATURE OF PHENOMENON: ssc, ssc*, si, si*, b, bp, bs, bps, pcl, pc2 - - pc5, pg, pi 1, pi 2, sfe. 


\begin{tabular}{|c|c|c|c|c|c|c|c|}
\hline \multirow{4}{*}{ 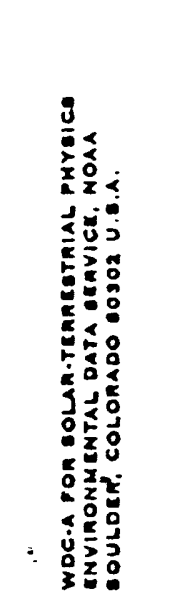 } & \multicolumn{2}{|c|}{ 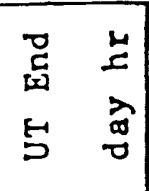 } & $\begin{array}{l}\text { t } \\
\text { no }\end{array}$ & $\begin{array}{l}\stackrel{\circ}{N} \\
\stackrel{\sim}{\circ}\end{array}$ & $\begin{array}{l}\underset{\gamma}{\sim} \\
\stackrel{\circ}{ }\end{array}$ & & \\
\hline & \multirow{3}{*}{ 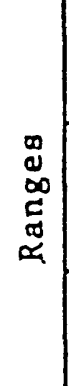 } & $\underset{N}{\overparen{E}}$ & 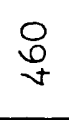 & 옴 & 8 & & \\
\hline & & $\widehat{\Xi}$ & $\stackrel{\stackrel{O}{\widetilde{W}}}{\sim}$ & 只 & $\begin{array}{l}0 \\
\infty \\
\rightarrow \\
ت\end{array}$ & & \\
\hline & & $\bar{\partial}$ & I্ & $\stackrel{\mathscr{n}}{n}$ & $\underset{r}{\stackrel{8}{2}}$ & & \\
\hline & \multirow{3}{*}{ 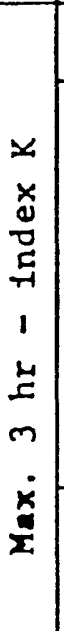 } & 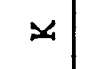 & s & 0 & 00 & & \\
\hline \multirow{5}{*}{ 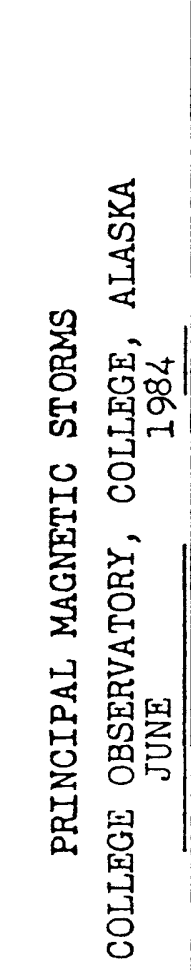 } & & 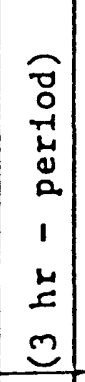 & in & 6 & . & $\ldots$ & \\
\hline & & 离 & n & $\stackrel{2}{\sim} \underset{-1}{ }$ & $\underset{\sim}{\infty} \underset{\sim}{-1}$ & & \\
\hline & \multirow{3}{*}{ 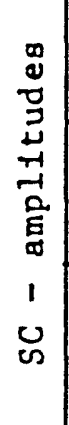 } & స్ & : & : & : & & \\
\hline & & $\begin{array}{l}\hat{\Xi} \\
\mathbf{x} \\
\end{array}$ & : & : & : & & \\
\hline & & $\check{z}$ & : & : & : & & \\
\hline \multirow{3}{*}{$\begin{array}{l}\text { a0 } \\
0 \\
0 \\
0 \\
0 \\
0 \\
0\end{array}$} & \multirow{3}{*}{ 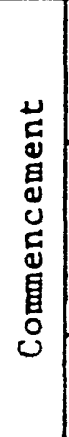 } & $\begin{array}{l}0 \\
\vdots \\
\vdots \\
\vdots\end{array}$ & : & : & : & & \\
\hline & & 돕엽 & $\begin{array}{l}x \\
0 \\
0 \\
0\end{array}$ & $\begin{array}{l}\qquad \\
\infty \\
0\end{array}$ & 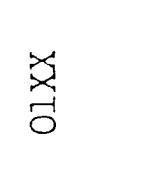 & & \\
\hline & & 元 & o & $\stackrel{n}{\sim}$ & $\stackrel{\infty}{r}$ & . & - \\
\hline \multirow{2}{*}{ 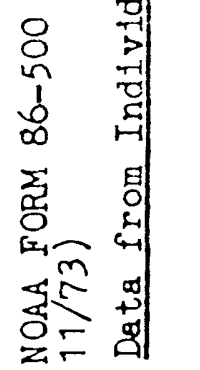 } & \multicolumn{2}{|c|}{ 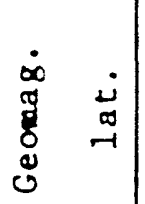 } & $\begin{array}{l}z \\
0 \\
0 . \\
0+ \\
0\end{array}$ & & & & \\
\hline & \multicolumn{2}{|c|}{ 罢 } & 8 & & & & \\
\hline
\end{tabular}




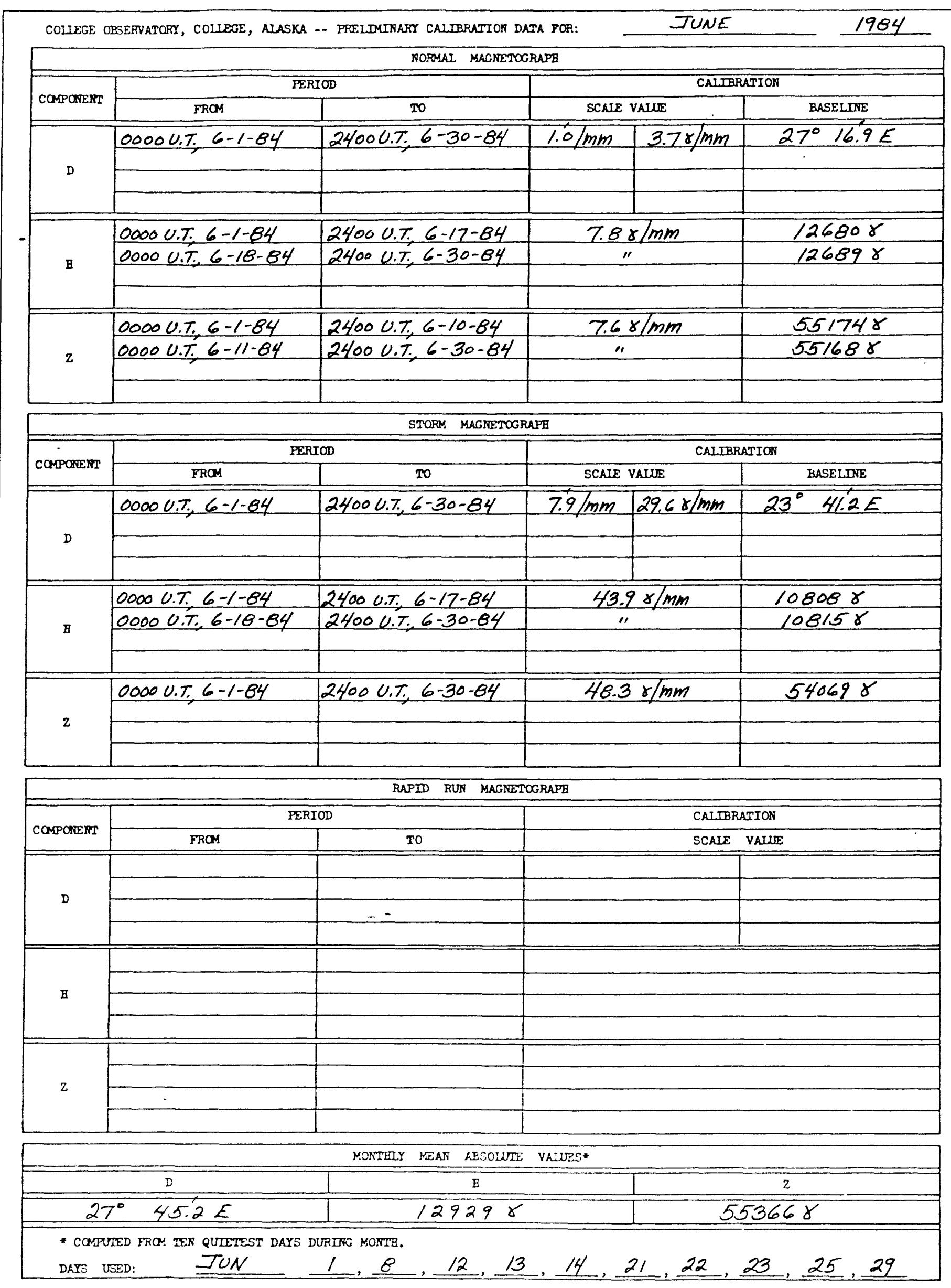




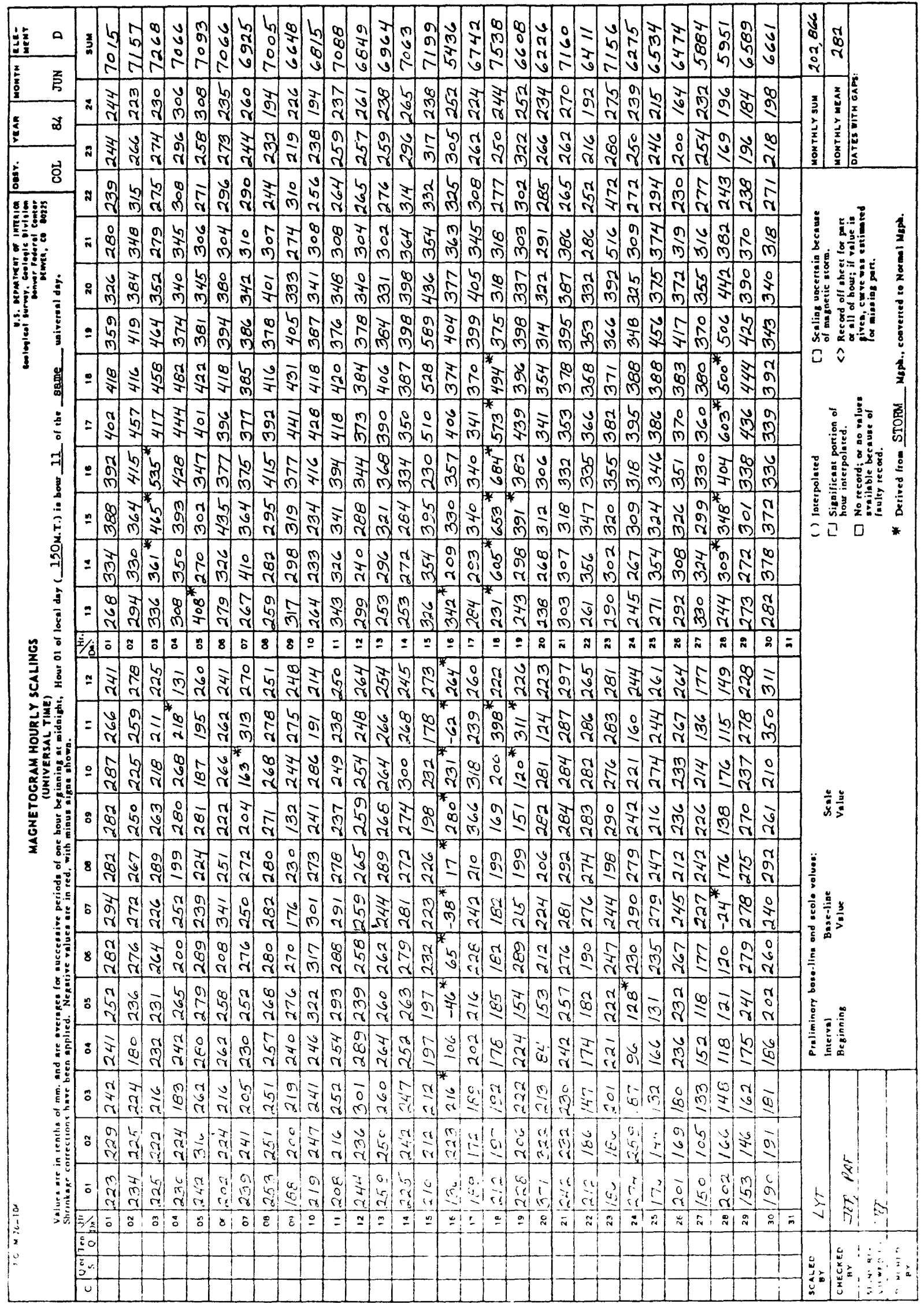




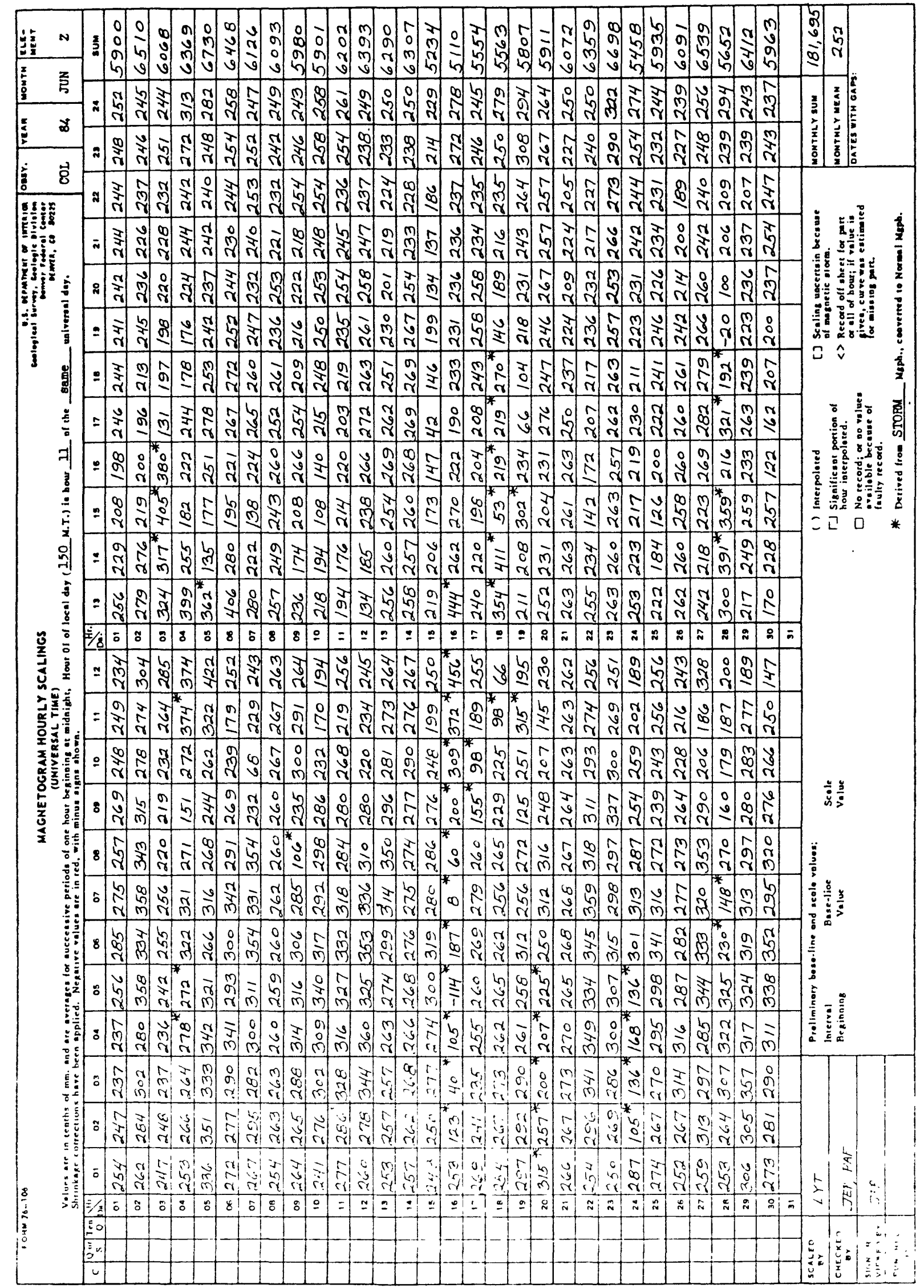




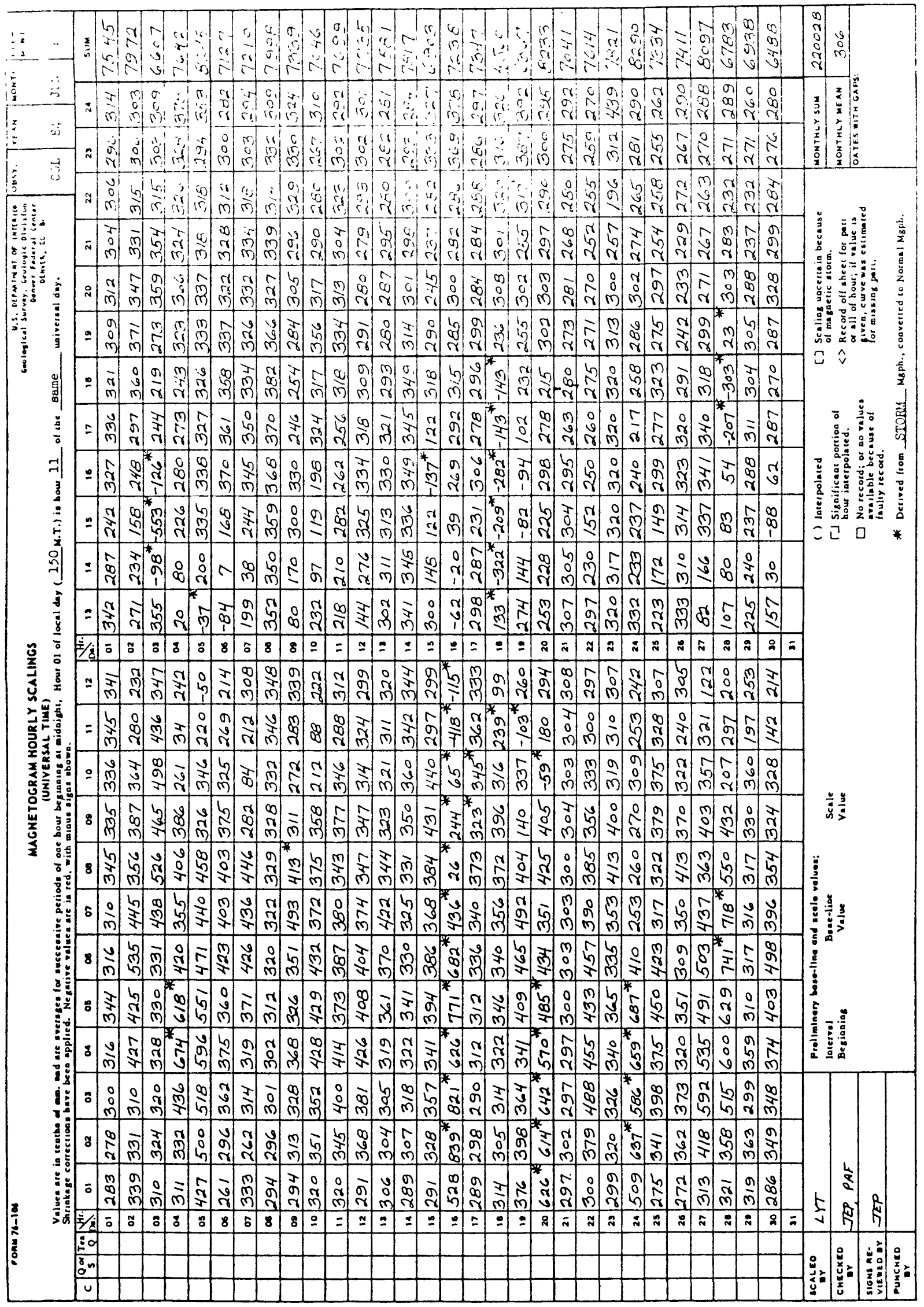




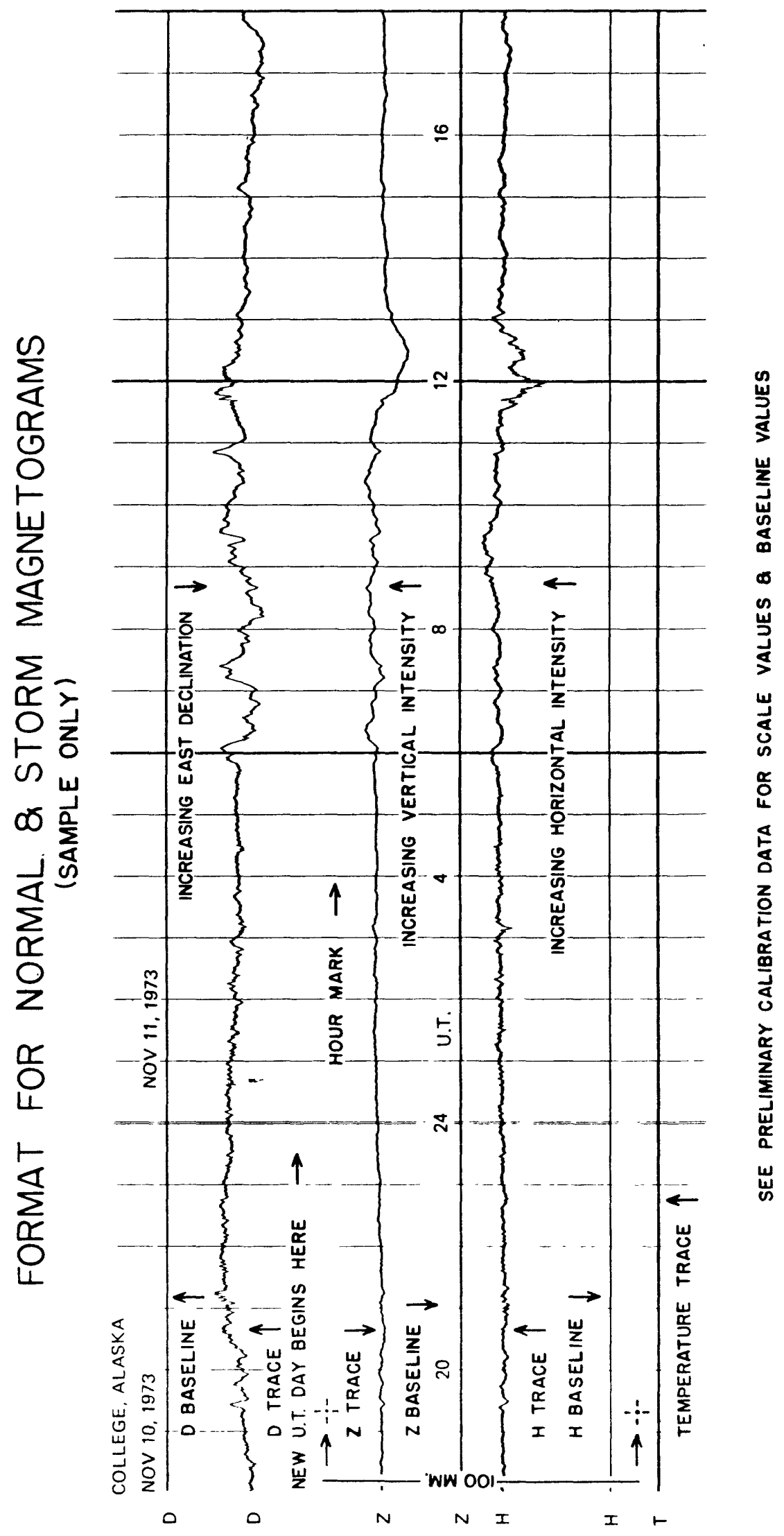



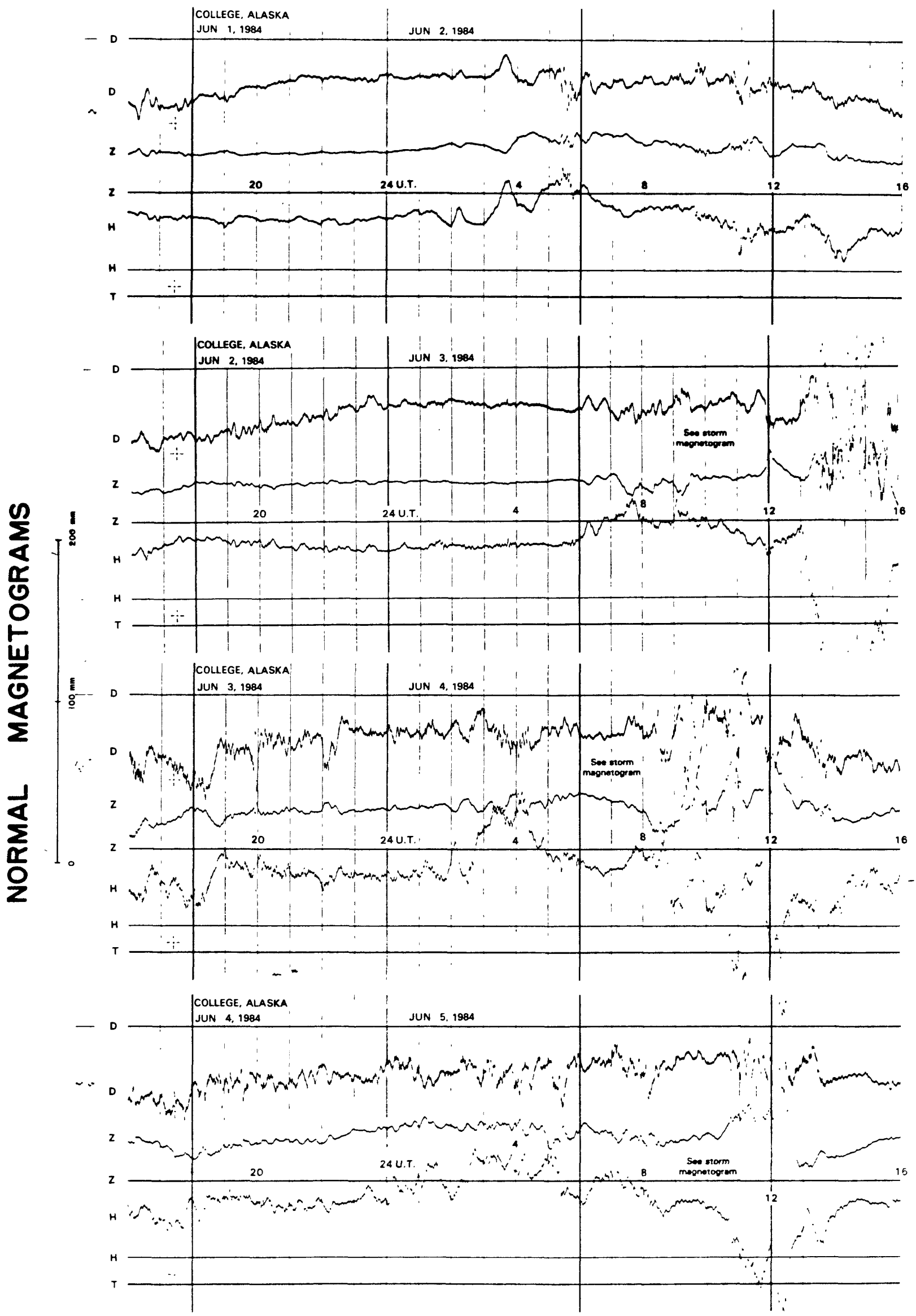


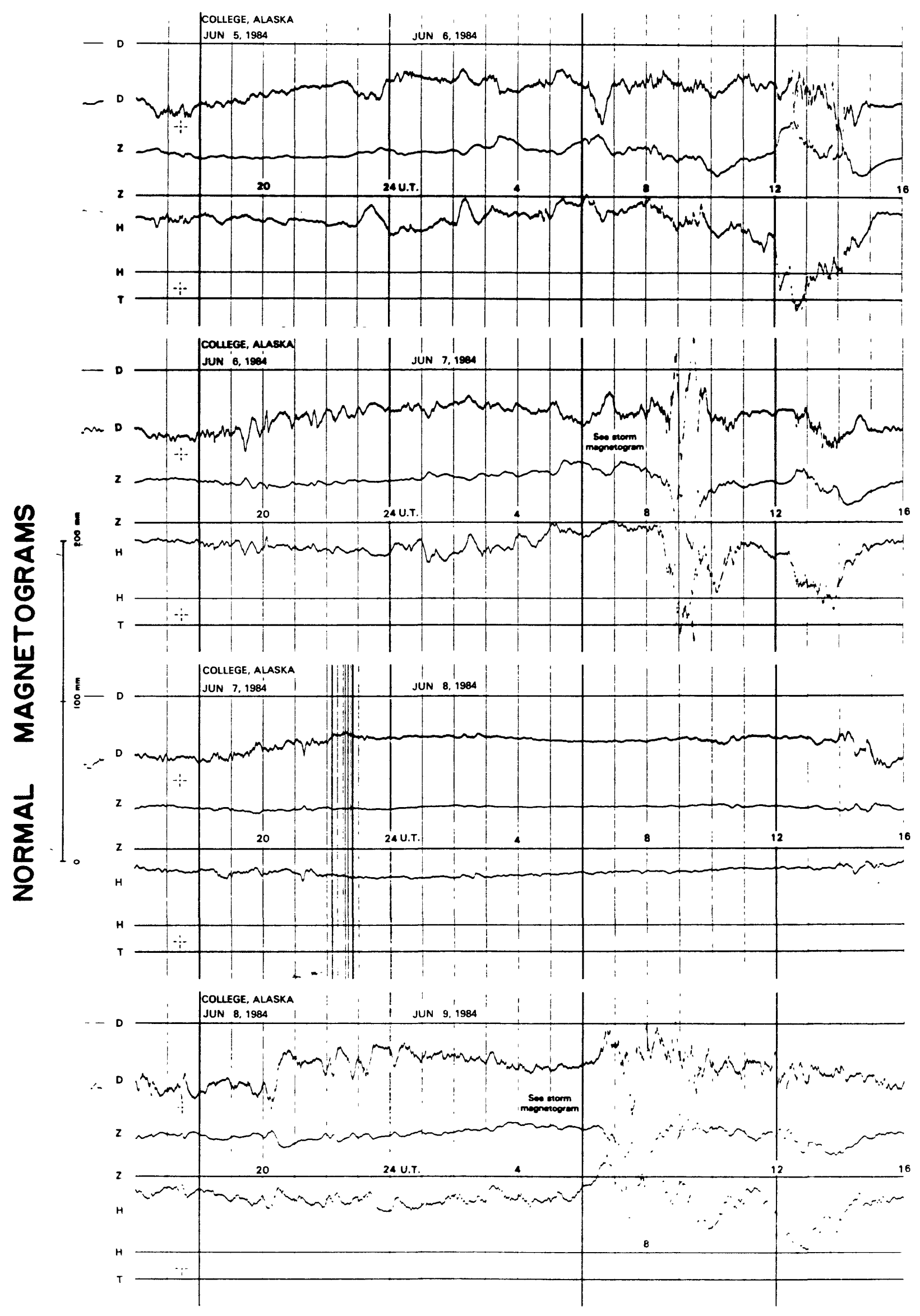




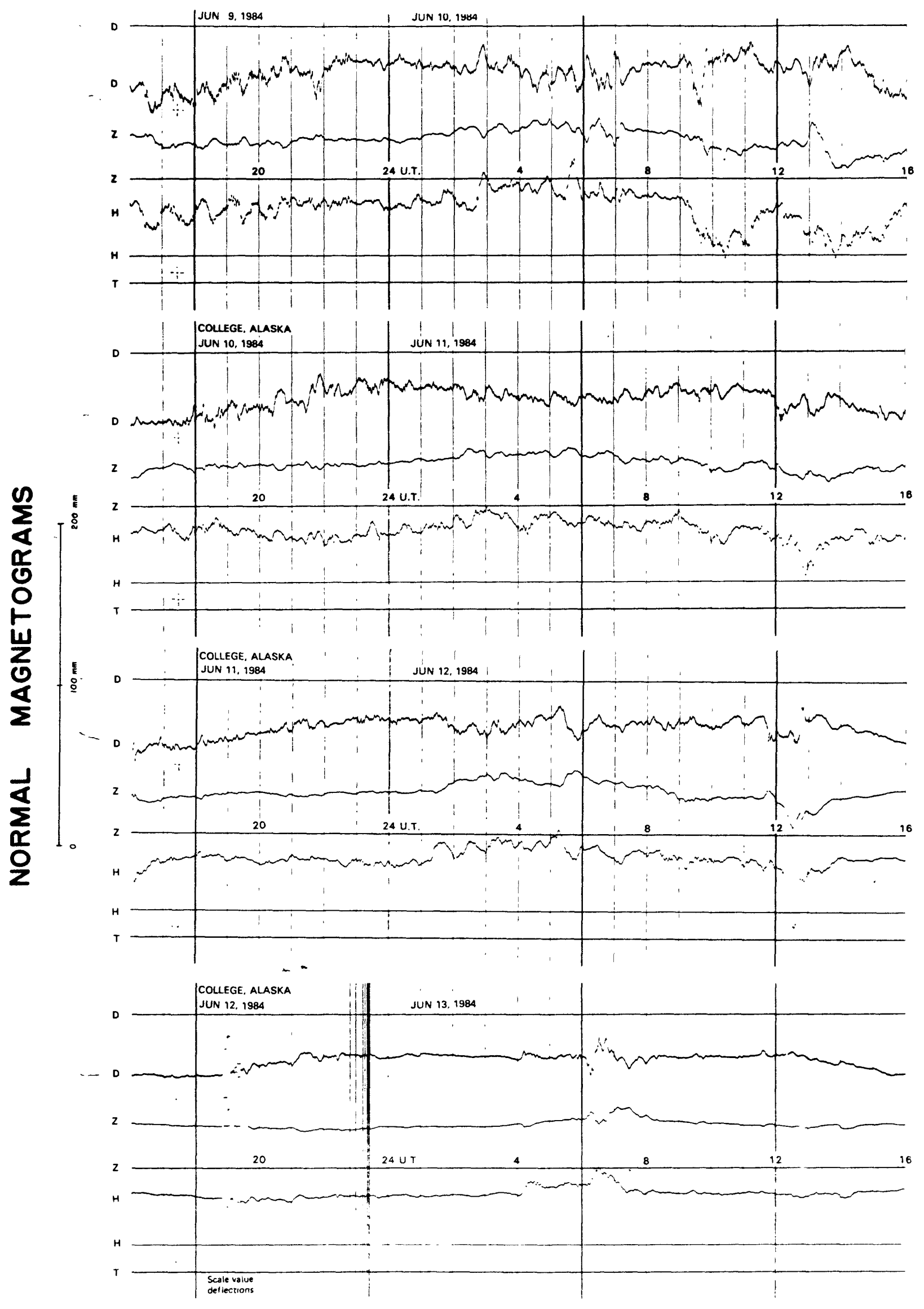




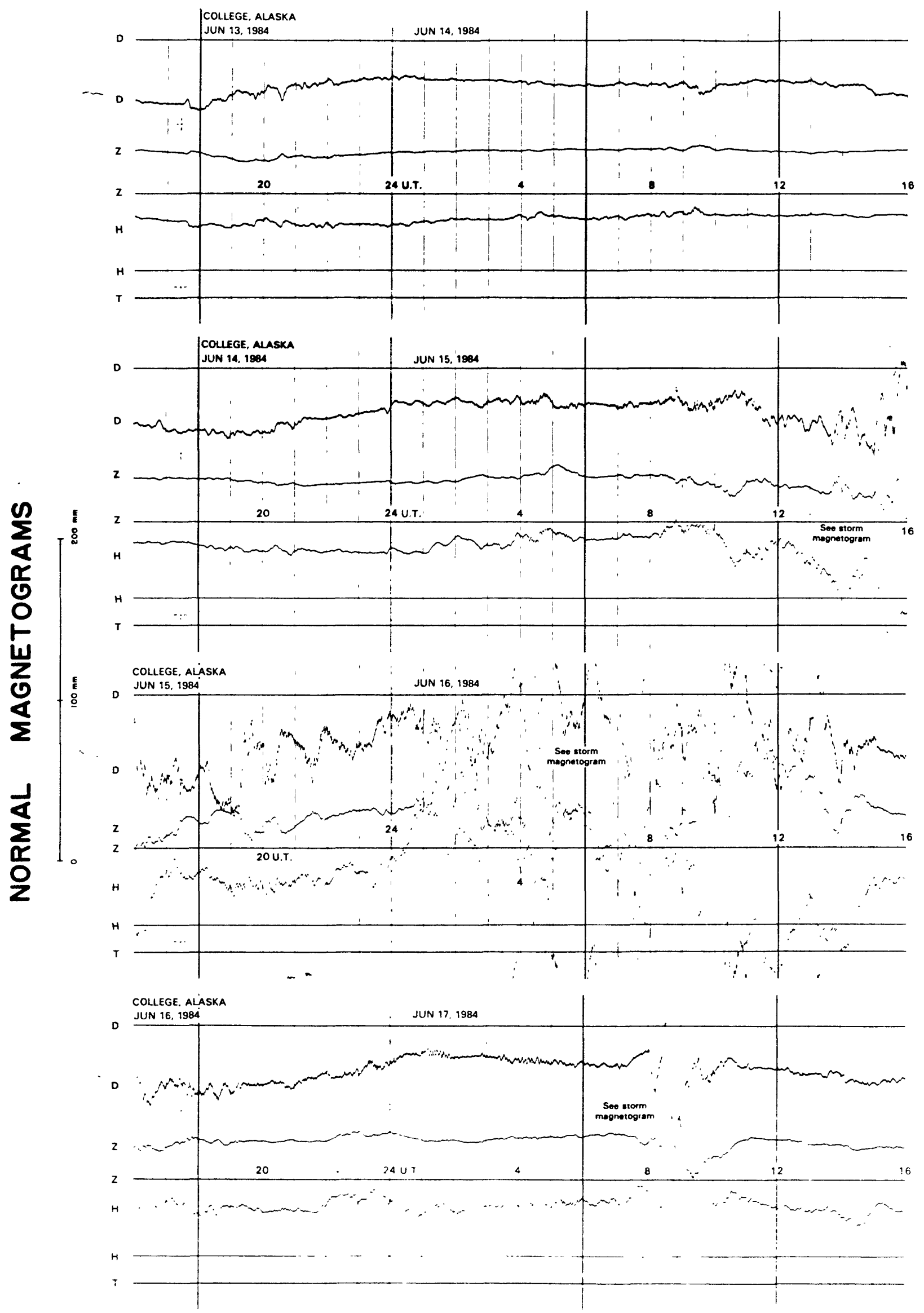




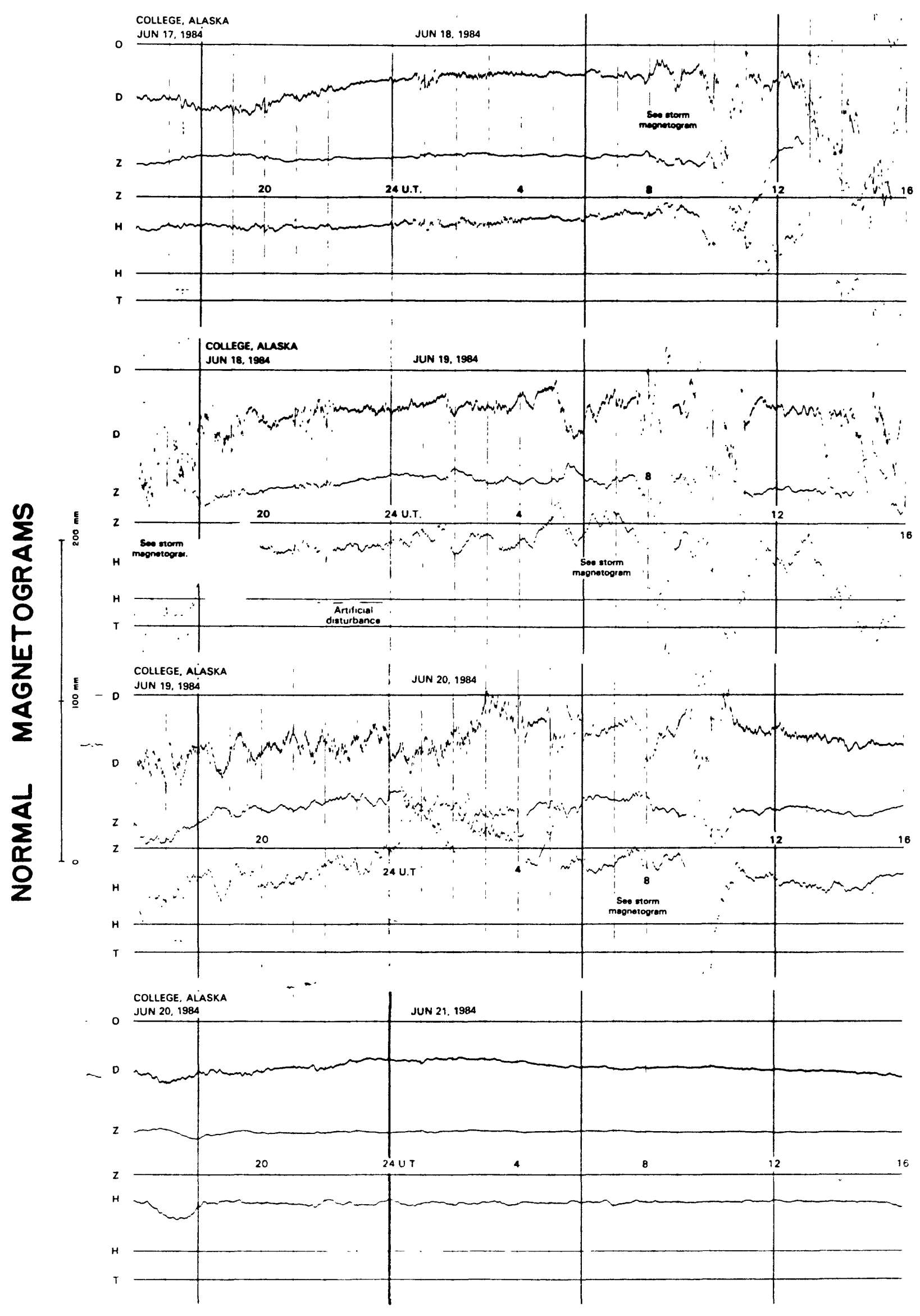




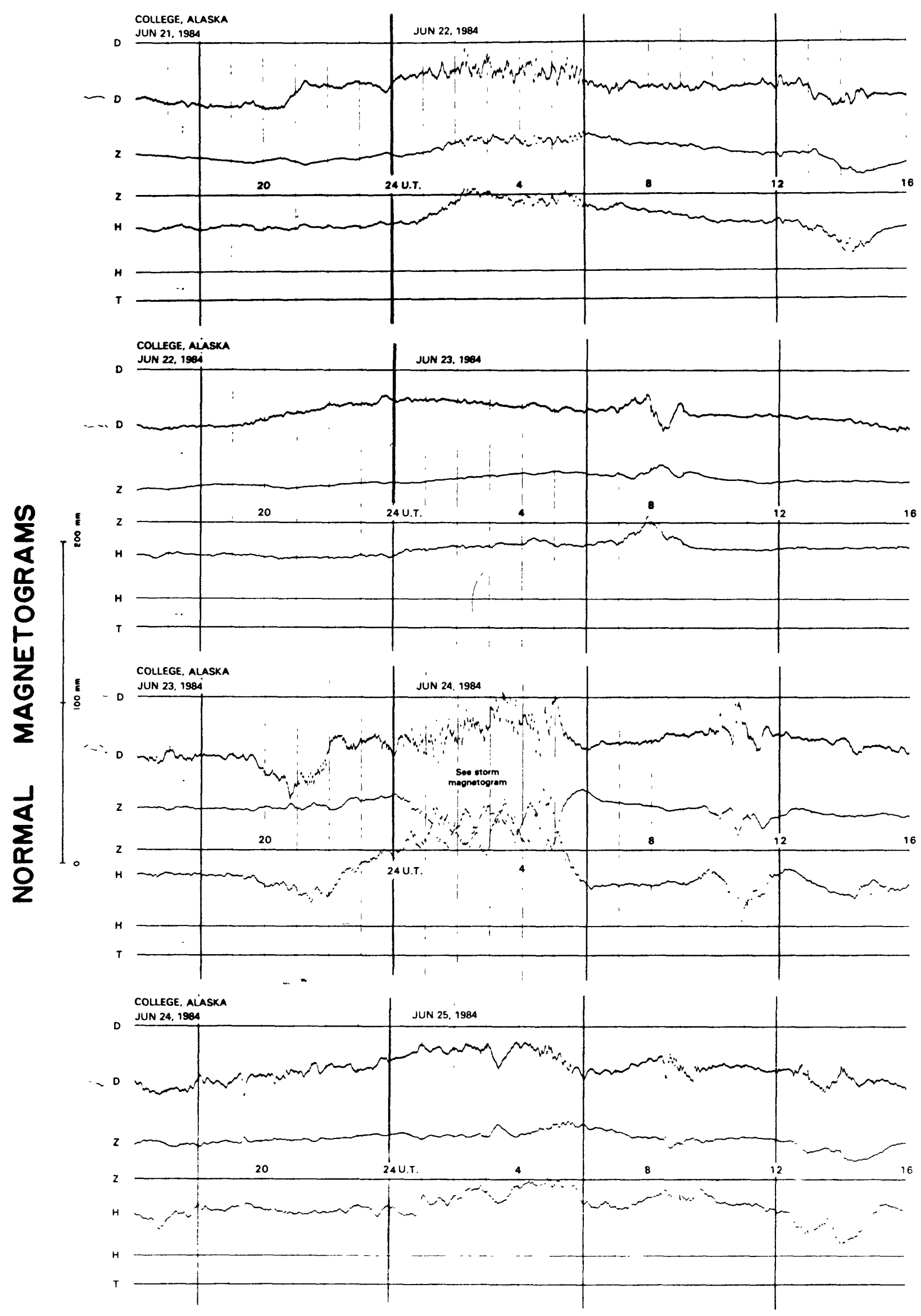




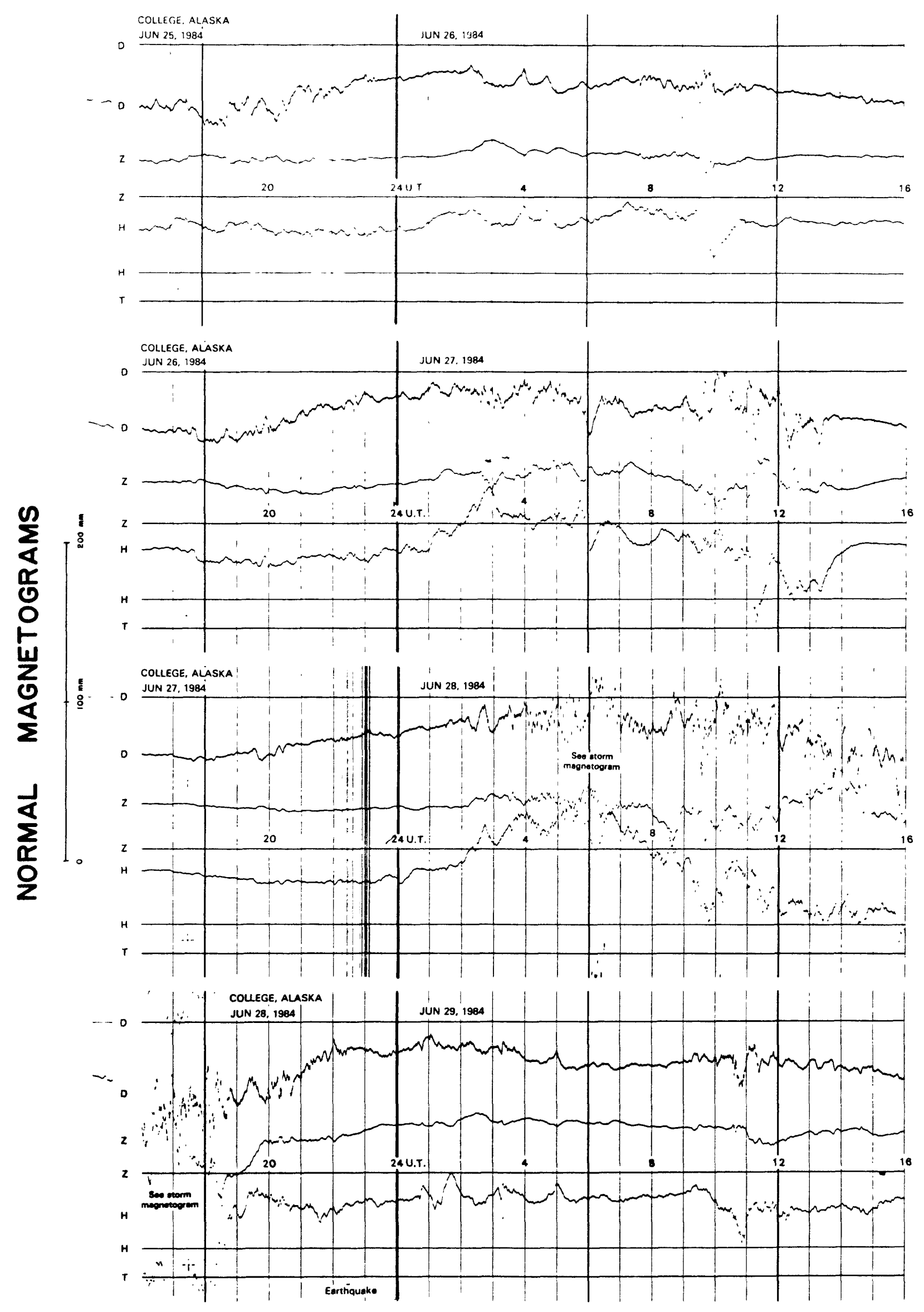




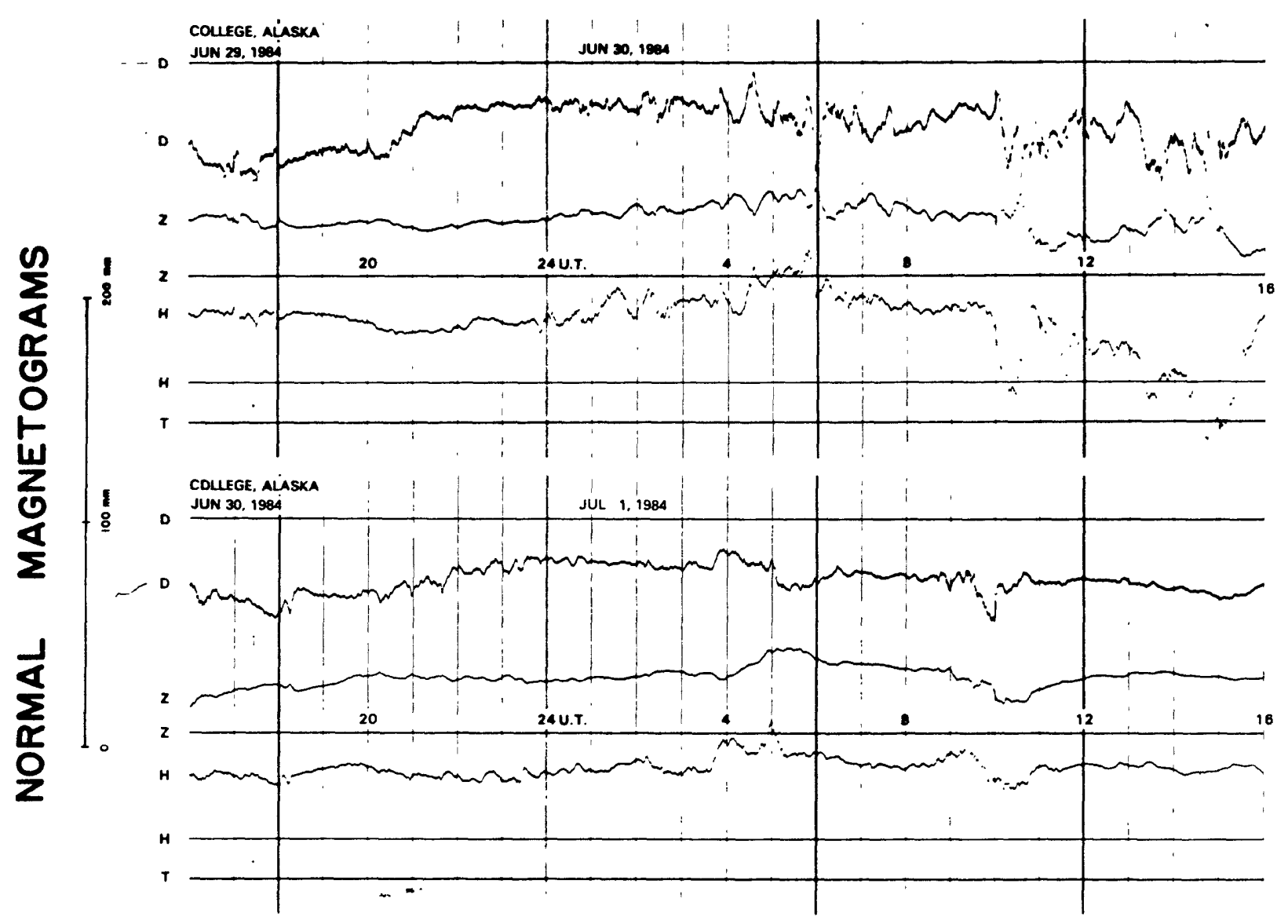




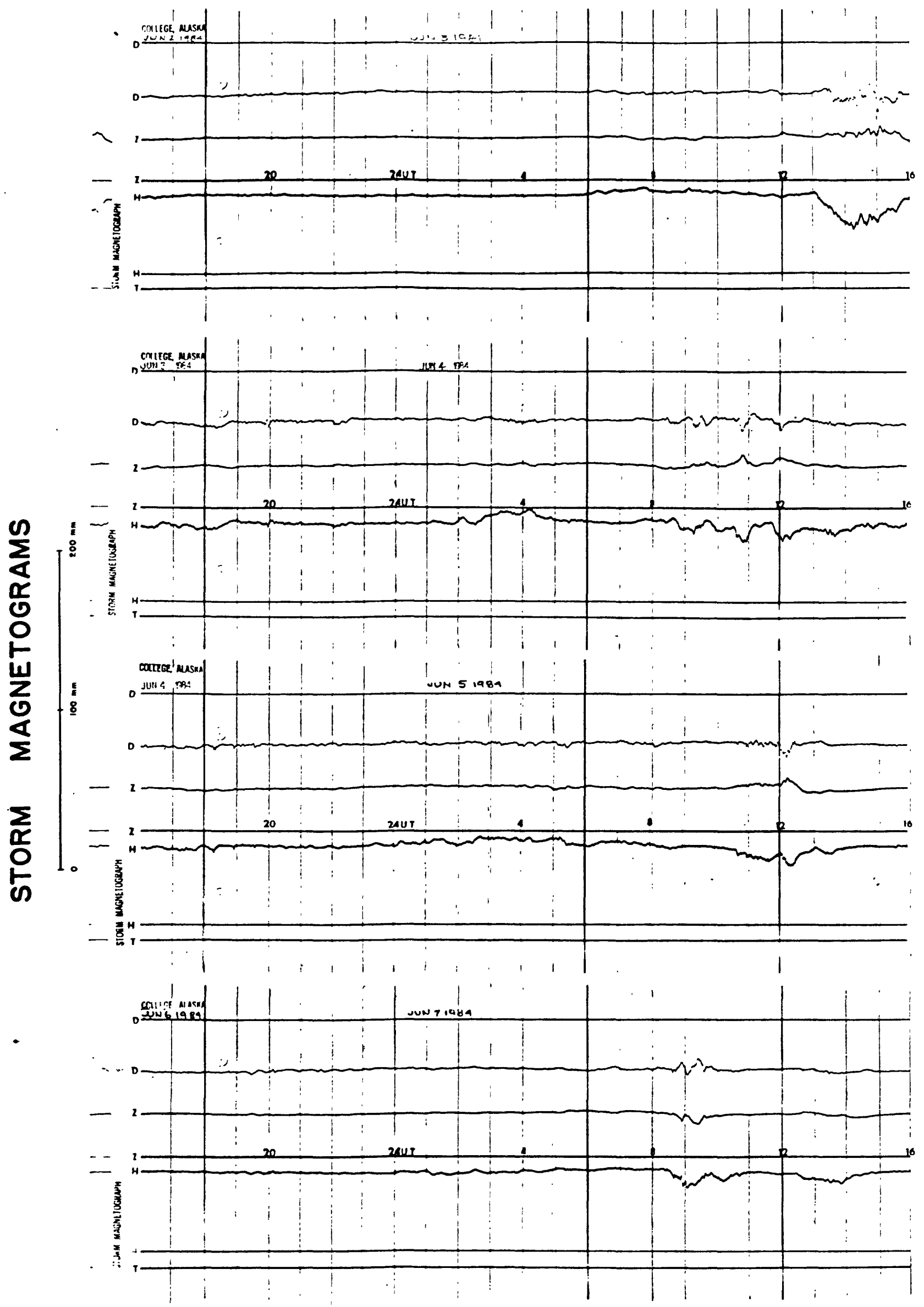




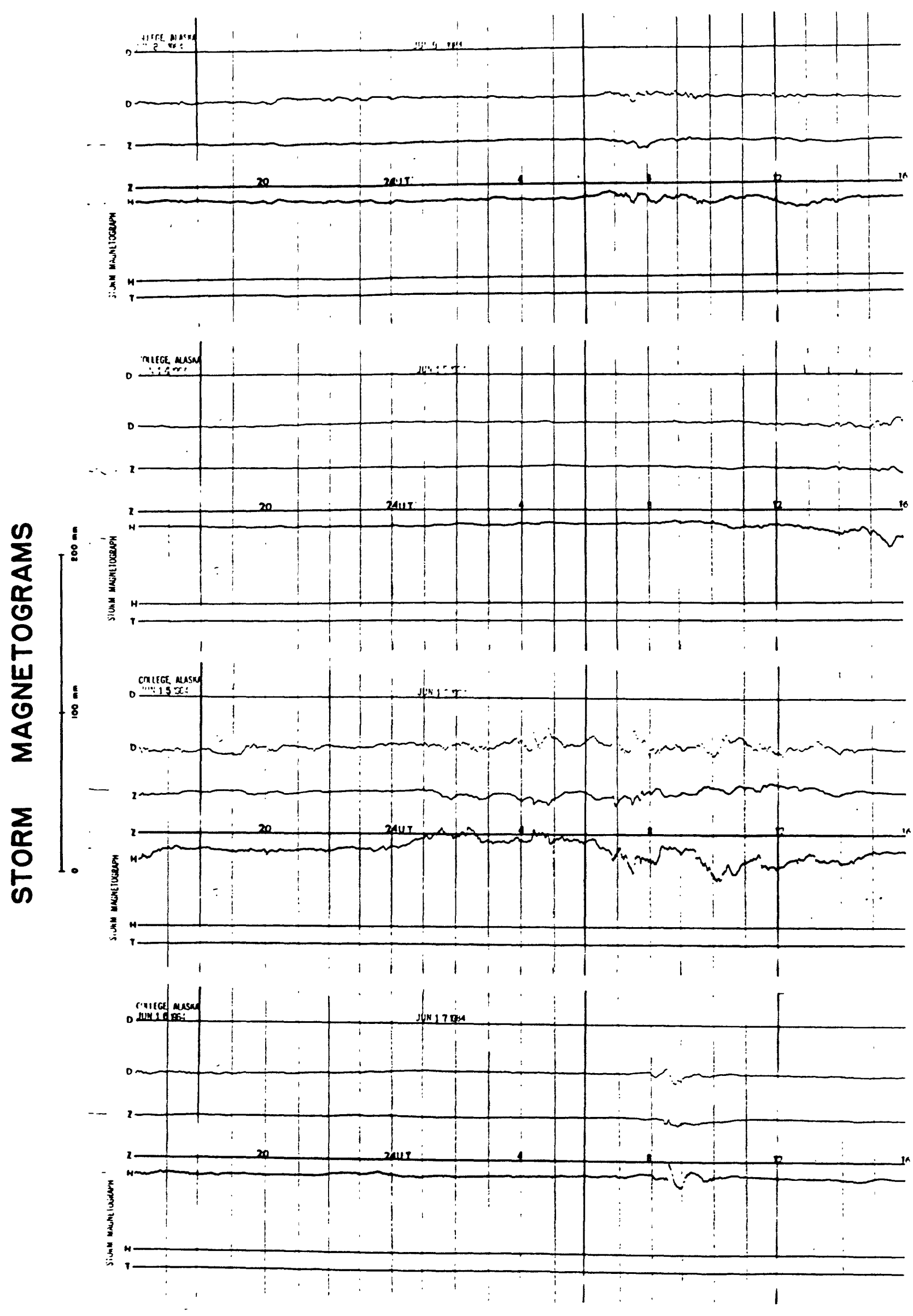




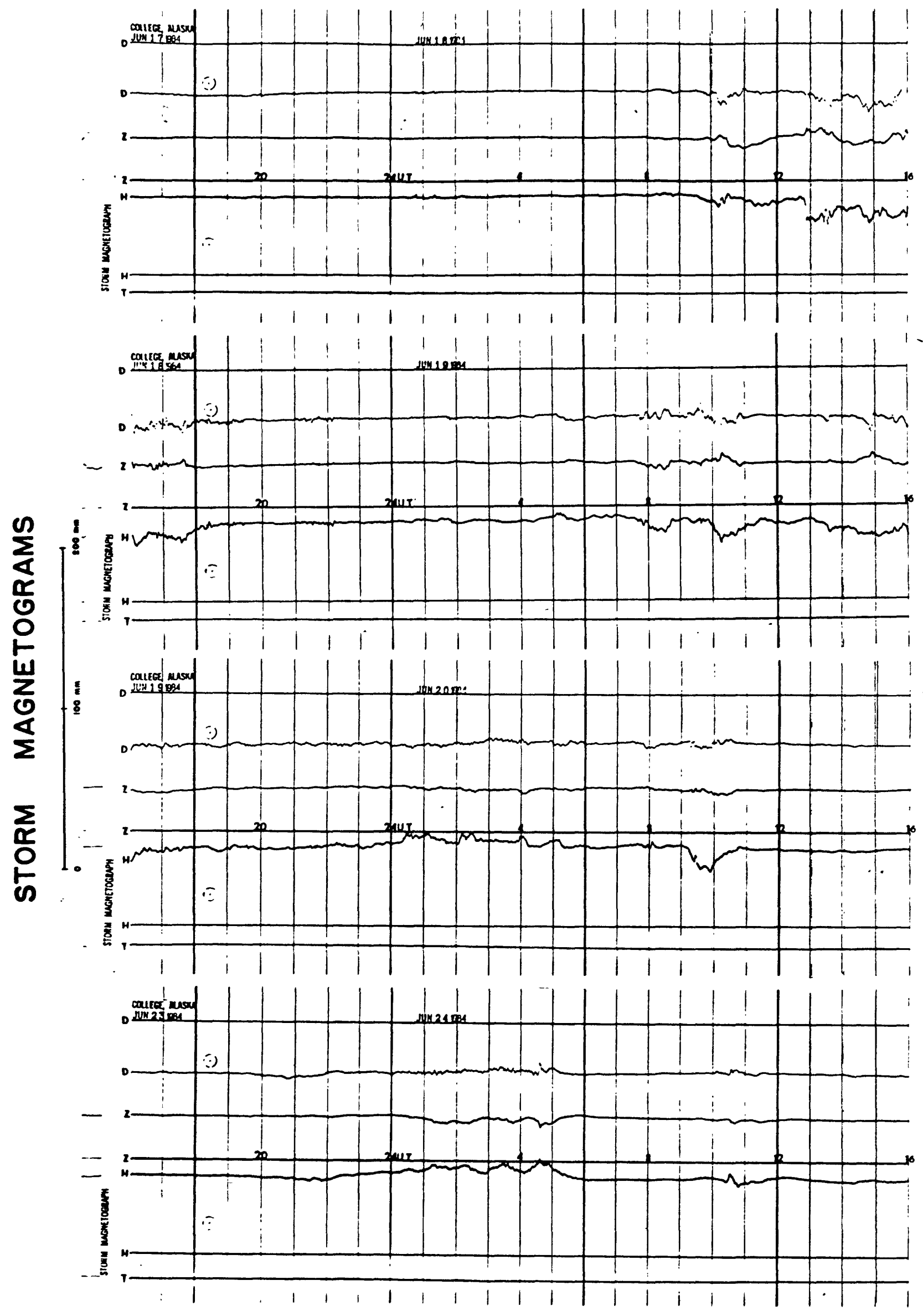




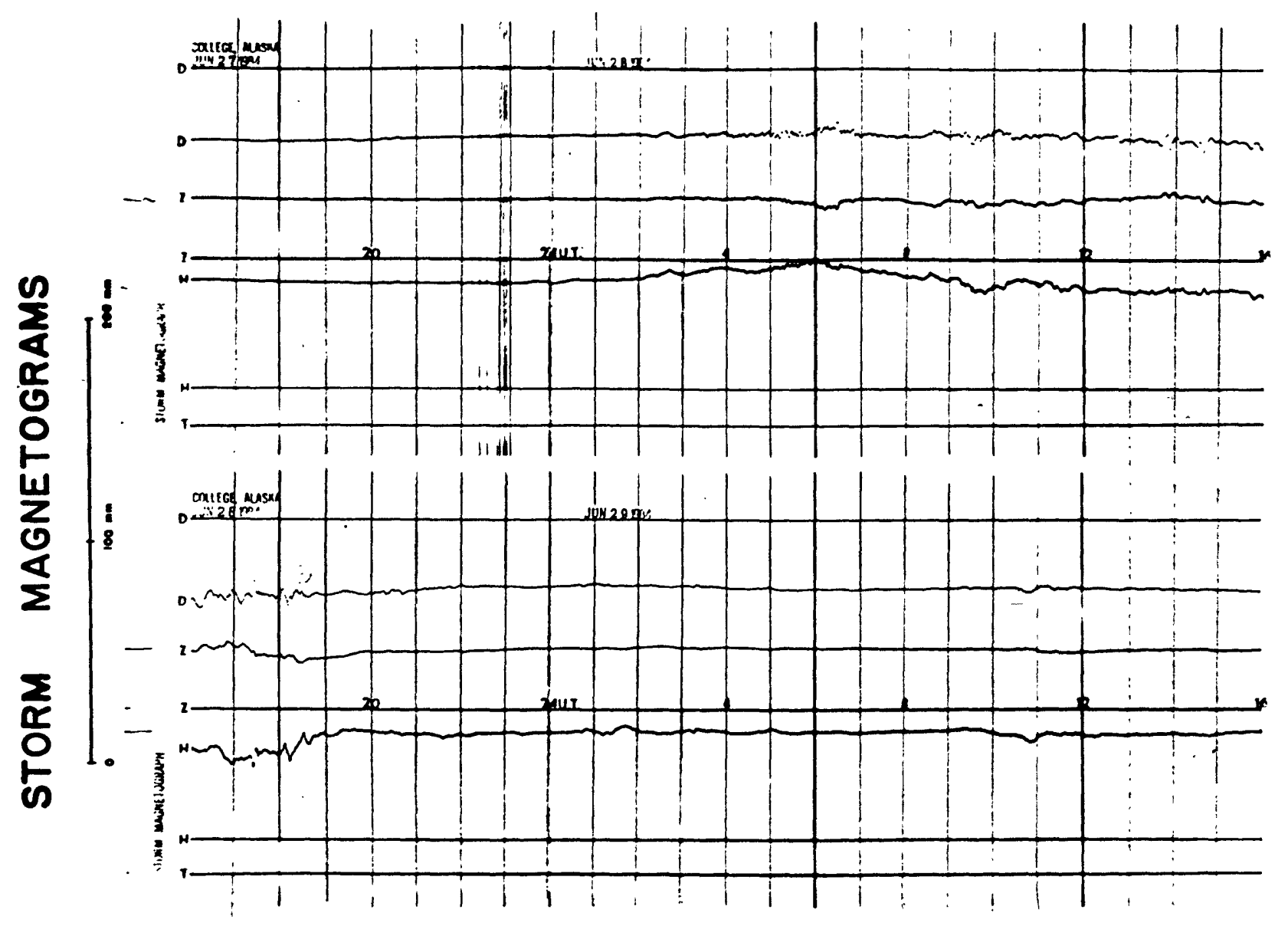

